\title{
A multi-criteria decision making approach for supplier selection in the flexible packaging industry
}

\author{
Ciprian Cristea $^{1, *}$, and Maria Cristea $^{1}$ \\ ${ }^{1}$ Faculty of Electrical Engineering, Technical University of Cluj-Napoca, Romania
}

\begin{abstract}
The supplier selection problem represents one of the most important components of the supply chain management. This article presents a multiple criteria decision making analysis contributing to the selection of the most convenient supplier in the flexible packaging industry. Due to the fact that in today's supply chain management, the performance of potential suppliers is evaluated against multiple criteria rather than taking into account only the cost factor, the appropriate criteria in the supplier selection have been identified, and the considered variants are assessed, considering the decision maker's preferences and existing constraints. The variants are ranked in terms of their suitability for selecting a supplier with the use of Electre III method. The results obtained from the simulation experiment suggest that this methodology is a feasible decision support model.
\end{abstract}

\section{Introduction}

In order to be up-to-date and feasible on the contemporary global market, characterized by issues like intense competition, high consumer expectations for quality products and services, low profit margins and short lead-times, enterprises need to take the advantage of any opportunity to improve their business processes [1]. Firms realize the significance of supply chain management in their organizations due to the fact that their success is not achievable without an efficient one which plays an important role in the attainment of sustained competitive advantage on the market. Supply chain management represents the overview of the product's lifecycle: from the supply which focuses on obtaining raw materials, to the manufacturing of the product that focuses on transforming the obtained raw materials into finished products, to their distribution to customers through distributors, warehouses and retailers [2]. Supplier selection occupies an important position in the supply chain management, and is a research area that continually receives a relatively large amount of attention in the literature, from both practitioners and academics.

Supplier selection is the process by which companies identify, evaluate and choose the suppliers to become part of their supply chain. The main objective of the supplier selection process is to maximize overall value to the purchaser, reduce acquisition risk, and build a close and long term relationships between buyers and suppliers [3]. The selection of the

\footnotetext{
* Corresponding author: ciprian.cristea@emd.utcluj.ro
} 
right suppliers is essential for enhancing the enterprises' competitiveness and to promptly react to market requirements and innovation process [4]. Likewise, selecting the right suppliers can decrease operational costs and delivery time [5]. In today's financial and production environment, manufacturing firms depend very much on suppliers for providing materials and components used in finished products, whereas the costs of raw materials and component parts constitute approximately $50 \%$ to $70 \%$ of the production costs [6]. Previous studies revealed that cost is not the only criterion to be considered when enterprises select the preferred suppliers. The selection of appropriate suppliers implies consideration of multiple qualitative and quantitative criteria. Thus, in [7] quality is considered the critical criterion, followed by deliverability, price, manufacturing capability, service, management, and technology.

Supplier selection problem received a lot of attention recently. Multiple studies using different analysis methods have been performed. Some of the methods mentioned in literature are: analytical hierarchy process (AHP) [8], analytic network process (ANP) [9], data envelopment analysis (DEA) [10], Elimination and Choice Expressing Reality (ELECTRE) [11], Preference Ranking Organisation Method for Enrichment Analysis (PROMETHEE) [12], Techniques for Order Performance by Similarity to Ideal Solution (TOPSIS) [13], game theory [14], linear programming [15], non-linear programming [16], multi-objective programming [17], goal programming [18], stochastic programming [19], mixed integer programming [20] and mixed integer nonlinear programming [21], genetic algorithm [22], grey system theory [23], neural network [24], Bayesian networks [25], decision tree [26], case based reasoning [27], ant colony algorithm [28], and their hybrids.

The rest of the paper is organized as follows: in the second section the methodology of multiple criteria decision making is presented. The third section describes the case study based action research for the supplier performance evaluation within a large company performing in the field of flexible packaging production. The variants (suppliers), evaluation criteria and decision making's preferences are detailed in this section. Furthermore, the results of the computational experiments are presented in the fourth section and, finally, the last section summarizes the conclusions.

\section{Methodology}

Selecting the suitable supplier considerably decreases purchasing costs, improves competitiveness in the market, enhances supply chain performance and improves end-user satisfaction. Due to the strategic importance, various decision makers from departments other than purchasing such as finance, production, and marketing are frequently involved in the decision making process for the supplier selection process [1]. The process of selecting the supplier implies the evaluation of various suppliers based on diverse quantitative and qualitative criteria. Therefore, choosing the right suppliers is considered a multiple criteria decision-making problem.

Multi-criteria decision-making is probably the most widely used decision methodology in the business and engineering fields, being able to improve the quality of decisions by making the process more efficient, rational and explicit [29]. The decision processes may be divided into two stages. The first stage is evaluation. The assessment criteria used to measure the performance of diverse alternatives of the problem are established. The alternatives of the problem are assessed through the pre-determined criteria. This stage requires the knowledge of experts to qualitatively and/or quantitatively evaluate each alternative under each defined criterion. The outcome of this stage is frequently a matrix, called the decision matrix, composed of the alternatives as its rows and the criteria as its columns. The performances of alternatives under each criterion are found in its cells. The 
second stage of the decision-making process consists of the ranking and selecting the alternatives based on their performances [30].

The ELECTRE III method was chosen because it can develop the analysis better than other multiple criteria decision making methods; likewise for its capability to deal with imprecise, inaccurate, uncertain data, inevitable to complex processes in complicated human decision [31]. The ELECTRE III method is based on the application of the outranking relation, in order to rank a finite set of alternatives from the best to the worst, based on using a set of evaluation criteria, and on the preferential information submitted by the decision makers [32].

The computational algorithm of the ELECTRE III method includes the following three phases [32-34]:

a. Establishing a set of alternatives $(A)$ and a family of criteria $(F)$ combined with the construction of a performance matrix. In this phase, the preferential information is given by the decision makers in the form of criteria weights $(w)$ and the indifference $(q)$, preference $(p)$ and veto $(v)$ thresholds.

b. Construction of the outranking relation $(S(a, b))$ is a result of computation procedure, which indicates the extent to which "alternative $(a)$ outranks alternative $(b)$ " overall. The outranking relation is built on the basis of concordance and discordance tests. The concordance index indicates the truth of the statement "alternative $(a)$ outranks alternative (b)". The value of concordance index is between 0 and 1 . The global concordance indicator is determined as the weighted sum of concordance indexes for all criteria. The discordance test evaluates the strength of evidence against the statement "alternative $(a)$ outranks alternative $(b)$ ", which can be repealed if the difference of performance between alternative (a) and alternative $(b)$, on any criterion is higher than the veto threshold. The value of this index is between 0 and 1 . The outranking relation is expressed by the degree of credibility $(d(a, b))$. It is an equivalent of the global concordance indicator $(C(a, b))$ determined in the concordance test weakened by the discordance indexes $\left(D_{j}(a, b)\right)$ computed in discordance test. The values of the credibility degree range between 0 and 1 .

c. Exploitation of the outranking relation $(S(a, b))$. Based on the calculation of the credibility degree the method establishes two preliminary rankings using the distillation procedure. Using this procedure a descending and an ascending preorder can be acquired. The final ranking is presented either in the form of the ranking matrix or the outranking graph, as the results of intersection of the above mentioned complete preorders.

\section{Case study}

In order to illustrate the implementation of the proposed decision making method to the supplier selection problem, a case study conducted in collaboration with the management of a large leading firm performing in the field of flexible packaging production is presented. The company has manufacturing facilities in Romania and other facilities in Europe, being capable of timely responding to market needs in terms of quality, flexibility and production standards. To ensure a strategic cultural and operating closeness to the global end users, the company's subsidiaries are based near their customers. The firm exports its products to most of the major markets across the world.

This case study deals with supplier selection among a set of seven candidates (Alpha, Beta, Gamma, Delta, Epsilon, Zeta and Eta), which can provide materials according to a set of requirements indicated by the company. Most of the case firm's suppliers are in foreign countries. The evaluation was performed by three decision-makers, managers representing three different corporate functions (sales, engineering and finance departments), whose various point of views have to be comprised in the model. The decision makers were 
interviewed for identifying the adequate criteria, weights, and the rates of the evaluated suppliers. The weights and the value of thresholds are depicted in table 1.

Table 1. Thresholds and criteria weights.

\begin{tabular}{|c|c|c|c|c|}
\hline Criteria & Indifference $q$ & Preference $p$ & Veto $v$ & Weights \\
\hline $\mathrm{C}_{\mathrm{I}}$ & 0.2 & 0.4 & 0.6 & 0.2 \\
\hline $\mathrm{C}_{\text {II }}$ & 0.1 & 0.2 & 0.4 & 0.1 \\
\hline $\mathrm{C}_{\text {III }}$ & 0.2 & 0.3 & 0.5 & 0.08 \\
\hline $\mathrm{C}_{\text {IV }}$ & 0.15 & 0.2 & 0.5 & 0.05 \\
\hline $\mathrm{C}_{\mathrm{v}}$ & 0.1 & 0.2 & 0.4 & 0.05 \\
\hline $\mathrm{C}_{\mathrm{VI}}$ & 0.15 & 0.2 & 0.6 & 0.03 \\
\hline $\mathrm{C}_{\text {VII }}$ & 0.15 & 0.2 & 0.6 & 0.01 \\
\hline $\mathrm{C}_{\text {VIII }}$ & 0.1 & 0.15 & 0.4 & 0.03 \\
\hline $\mathrm{C}_{\text {IX }}$ & 0.1 & 0.2 & 0.5 & 0.03 \\
\hline$C_{x}$ & 0.1 & 0.2 & 0.3 & 0.01 \\
\hline $\mathrm{C}_{\mathrm{XI}}$ & 0.1 & 0.3 & 0.6 & 0.04 \\
\hline $\mathrm{C}_{\mathrm{XII}}$ & 0.15 & 0.3 & 0.5 & 0.03 \\
\hline $\mathrm{C}_{\text {XIII }}$ & 0.1 & 0.3 & 0.6 & 0.02 \\
\hline $\mathrm{C}_{\mathrm{XIV}}$ & 0.1 & 0.3 & 0.5 & 0.01 \\
\hline $\mathrm{C}_{\mathrm{XV}}$ & 0.1 & 0.2 & 0.6 & 0.02 \\
\hline $\mathrm{C}_{\mathrm{XVI}}$ & 0.1 & 0.3 & 0.6 & 0.05 \\
\hline $\mathrm{C}_{\text {XVII }}$ & 0.05 & 0.3 & 0.7 & 0.05 \\
\hline $\mathrm{C}_{\text {XVIII }}$ & 0.1 & 0.2 & 0.5 & 0.04 \\
\hline $\mathrm{C}_{\mathrm{XIX}}$ & 0.1 & 0.15 & 0.4 & 0.03 \\
\hline$C_{x x}$ & 0.1 & 0.2 & 0.3 & 0.01 \\
\hline $\mathrm{C}_{\mathrm{XXI}}$ & 0.1 & 0.3 & 0.7 & 0.03 \\
\hline $\mathrm{C}_{\text {XXII }}$ & 0.1 & 0.2 & 0.5 & 0.04 \\
\hline$C_{\text {XXIII }}$ & 0.1 & 0.2 & 0.5 & 0.04 \\
\hline
\end{tabular}

The decision makers have proposed 23 criteria $\left(\mathrm{C}_{\mathrm{I}}\right.$ to $\left.\mathrm{C}_{\mathrm{XXIII}}\right)$ in order to perform a complete evaluation of the suppliers. The determined criteria are presented as follows.

Price $\left(\mathrm{C}_{\mathrm{I}}-[\right.$ Euro/kg] $)$ has a crucial role in supporting managers to make a decision because the cost of raw materials and component parts represent approximately $50 \%$ to $70 \%$ of the production costs. In a competitive manufacturing environment many companies are forced to adopt target costing for achieving consistent profitability. Quality $\left(\mathrm{C}_{\mathrm{II}}-\right.$ [points]) of the raw materials delivered by the supplier must conform to a set of technical properties (dynamic COF (coefficient of friction), heat seal range, seal strength, oxygen permeability, water permeability, corona treatment level, optical density, haze) request by the firm.

Payment terms $\left(\mathrm{C}_{\mathrm{III}}-\right.$ [days] $)$ affect the firms' cash-flow. The shorter the term for the company s to pay its suppliers, the less money has on hand, fact which is not favorable for the cash-flow. Response time $\left(\mathrm{C}_{\mathrm{IV}}-\right.$ [points]) is increasingly appreciated taking into account the short deadlines, better production processes, reduced time-to-market, multiple marketing campaigns opportunities. Standard delivery period $\left(\mathrm{C}_{\mathrm{V}}-\right.$ [days] $)$ represents the normal time between the placement of an order and receipt of the delivery. Due to aggressive marketing strategies, in emergency situations, the supplier should be able to deliver sooner than standard delivery period. External audit results $\left(\mathrm{C}_{\mathrm{VI}}-\right.$ [points] $)$ could influence the customer's purchasing decisions. In order to ensure compliance to requirements, an audit can apply to a product, process, or to an entire organization.

Implemented ISO standards ( $\mathrm{C}_{\mathrm{VII}}-$ [points]) show that the supplier has a quality management system that meets the requirements and it has the ability to supply consistent, 
conforming products or services. Production capacity ( $\mathrm{C}_{\mathrm{VIII}}-$ [points]) and available production capacity $\left(\mathrm{C}_{\mathrm{IX}}\right.$ - [points]) are very important especially when the demand for the buyer's product is tied to unforeseen market events. Reputation $\left(\mathrm{C}_{\mathrm{X}}-\right.$ [points]) takes into account the performance history of the supplier, its size and feedback from its clients, previous global experience. Geographical location $\left(\mathrm{C}_{\mathrm{XI}}-\right.$ [points]) should be assessed carefully in order to eliminate the risk of disruption in the supply chain. Product diversity $\left(\mathrm{C}_{\mathrm{XII}}-\right.$ [points]) measures the ability of the suppliers to manufacture different products. Flexibility $\left(\mathrm{C}_{\mathrm{XIII}}-\right.$ [points]) refers to the ability of the supplier to adapt production resources in order to meet the changing demands of customers. Response to customer complaints $\left(\mathrm{C}_{\mathrm{XIV}}-\right.$ [points]) should be quick and efficient so as to keep customers happy and is critical to the success of any business. Customs duty and procedures $\left(\mathrm{C}_{\mathrm{XV}}-\right.$ [points] $)$ depends on the location the goods came from. Technology $\left(\mathrm{C}_{\mathrm{XVI}}-\right.$ [points]) of suppliers was assessed based on the type of processes, machinery and equipment. Likewise, access to appropriate manufacturing technologies and patents were evaluated.

On-time delivery $\left(\mathrm{C}_{\mathrm{XVII}}-\right.$ [points]) refers to the supplier's commitment to maintain the delivery schedule determined by the firm. Research \& development ( $\mathrm{C}_{\mathrm{XVIII}}-$ [points]) enables a supplier to improve its current technologies and products, and can boost its competitive advantage. Reliability of delivery ( $\mathrm{C}_{\mathrm{XIX}}-$ [points]) indicates the supplier's ability to predictably supply the requested products as promised. Financial strength $\left(\mathrm{C}_{\mathrm{XX}}-\right.$ [points]) is very important because a supplier should have adequate funds to deliver the products to the customer. The financial strength is evaluated based on the financial ratio, such as activity, profitability, liquidity and solvency. Warranty terms $\left(\mathrm{C}_{\mathrm{XXI}}-\right.$ [points]) represent a type of guarantee that a supplier makes based on terms and situations when replacements or repairs will be needed if the product does not have the properties as originally described for a set period of time. Communication $\left(\mathrm{C}_{\mathrm{XXI}}-\right.$ [points]) is essential in developing more collaborative and trusting relationships, especially when dedicated contact persons from the supplier for specific projects are assigned. Quality of the human resources $\left(\mathrm{C}_{\mathrm{XXIII}}-\right.$ [points]) depends on supplier employee's attitudes, competences and skills. A high quality of human resources represents a source of sustained competitive advantages.

Table 2 presents the performance of all the alternatives to be assessed with respect to the identified criteria that meet managers' expectations.

Table 2. Performance matrix.

\begin{tabular}{|c|c|c|c|c|c|c|c|}
\hline $\begin{array}{c}\text { Alternatives } \\
\text { Criteria }\end{array}$ & Alpha & Beta & Gamma & Delta & Epsilon & Zeta & Eta \\
\hline $\mathbf{C}_{\text {I }}$ & 1.65 & 1.6 & 1.65 & 1.68 & 1.55 & 1.55 & 1.5 \\
\hline $\mathbf{C}_{\text {II }}$ & 99 & 80 & 90 & 75 & 85 & 50 & 70 \\
\hline $\mathbf{C}_{\text {III }}$ & 120 & 90 & 90 & 90 & 90 & 60 & 30 \\
\hline $\mathbf{C}_{\text {IV }}$ & 80 & 70 & 60 & 65 & 90 & 90 & 50 \\
\hline $\mathbf{C}_{\mathbf{~}}$ & 60 & 30 & 45 & 45 & 45 & 21 & 70 \\
\hline $\mathbf{C}_{\text {VI }}$ & 49.5 & 42.5 & 45 & 40 & 35 & 30 & 35 \\
\hline $\mathbf{C}_{\text {VII }}$ & 33 & 26.67 & 30 & 30 & 26.67 & 20 & 23.33 \\
\hline $\mathbf{C}_{\text {VIII }}$ & 24.75 & 17.5 & 17.5 & 22.5 & 17.5 & 7.5 & 20 \\
\hline $\mathbf{C}_{\text {IX }}$ & 80 & 60 & 50 & 60 & 50 & 30 & 50 \\
\hline $\mathbf{C}_{\mathbf{X}}$ & 19.8 & 14 & 16 & 16 & 14 & 10 & 12 \\
\hline $\mathbf{C}_{\mathbf{X I}}$ & 90 & 99 & 70 & 60 & 60 & 99 & 50 \\
\hline $\mathbf{C}_{\mathbf{X I I}}$ & 24.75 & 17.5 & 20 & 22.5 & 20 & 5 & 12.5 \\
\hline $\mathbf{C}_{\mathbf{X I I}}$ & 10 & 16 & 10 & 10 & 14 & 18 & 10 \\
\hline $\mathbf{C}_{\mathbf{X I V}}$ & 30 & 23.33 & 26.67 & 23.33 & 20 & 16.67 & 16.67 \\
\hline $\mathbf{C}_{\mathbf{X V}}$ & 33 & 33 & 33 & 26.67 & 16.67 & 33 & 16.67 \\
\hline $\mathbf{C}_{\mathbf{X V I}}$ & 39.6 & 34 & 36 & 38 & 34 & 16 & 28 \\
\hline
\end{tabular}




\begin{tabular}{|l|c|c|c|c|c|c|c|}
\hline $\mathbf{C}_{\text {XVII }}$ & 18 & 18 & 17 & 16 & 14 & 16 & 12 \\
\hline $\mathbf{C}_{\text {XVIII }}$ & 28.29 & 20 & 25.71 & 28.29 & 22.86 & 2.86 & 14.29 \\
\hline $\mathbf{C}_{\text {XIX }}$ & 9.9 & 6 & 6 & 8 & 8 & 5 & 6 \\
\hline $\mathbf{C}_{\mathbf{X X}}$ & 12.38 & 10 & 11.25 & 12.38 & 8.75 & 6.25 & 11.25 \\
\hline $\mathbf{C}_{\mathbf{X X I}}$ & 49.5 & 40 & 45 & 45 & 35 & 25 & 30 \\
\hline $\mathbf{C}_{\text {XXII }}$ & 66 & 60 & 60 & 53.33 & 66 & 46.67 & 40 \\
\hline $\mathbf{C}_{\text {XXIII }}$ & 22 & 20 & 20 & 20 & 20 & 17.78 & 17.78 \\
\hline
\end{tabular}

\section{Results}

The application of ELECTRE III method to the supplier selection problem at a large company implies a significant amount of computation that, without the use of a specialized software package, is hardly imaginable. The computational experiments were performed using a software developed by the authors of this paper based on the ELECTRE III method algorithm. The software is a Windows Forms application, built using Microsoft .NET Framework and Visual Studio 2015. The language used is C\#, version 4.5, which is a powerful object-oriented programming language developed by Microsoft.

The user interface uses Windows Forms, which offer a lot of flexibility in gathering and displaying data, making use of complex controls such as the Data Grid View Control and the Tab Control. The first control displays and manipulates data displayed in a grid. It allows defining cells and adding rows. The second control defines a list of tabs, which are control containers, which can be brought into and out of view using a navigation bar. This simplifies the user interface and increases usability. The business logic is implemented using both user-defined data structures and existing data structures, such as the Dictionary, which stores key-value pairs, such as the column-name - column-value within a record of data. These data structures, coupled with the powerful concepts of object-oriented programming, like inheritance and polymorphism, help keep complexity small, while still remaining expressive. Data is saved in binary format on disk, using a process called serialization. It is fast and easy to import and export, while it remains inaccessible by other applications, thus improving integrity.

The developed software starts with a specified set of alternatives assessed on a wellfounded family of pseudo-criteria and aggregates these preferential data into a fuzzy outranking relation. Once the application is started, in order to create the supplier selection problem at the company performing in the field of flexible packaging production, criteria and alternatives are defined via File from menu bar. For every criterion, the direction of the preference has to be specified. The direction of the preference indicate if the criterion is diminishing, like for example the price of raw materials and component parts (the score of the criterion has to be minimized), or increasing, like for example the quality of the raw materials (the score of the criterion has to be maximized). Once the alternatives and criteria have been defined, the performance of the alternatives is entered by selecting Input/Performance Matrix from the menu bar. The user has to define the indifference, preference and veto threshold for each criterion via Input/Thresholds from menu bar. Table 1 and 2 summarize data that was loaded in the application. Having established the alternatives, criteria, performances and thresholds, the user may proceed to the calculation of data by selecting Action/Compute from the menu bar. In order to establish the sequence of alternatives using the processes assigned to the ELECTRE III, three types of complementary results (the concordance matrix, the discordance matrix and the credibility matrix) are returned by the application. Figure 1 shows the credibility matrix calculated by the application. 


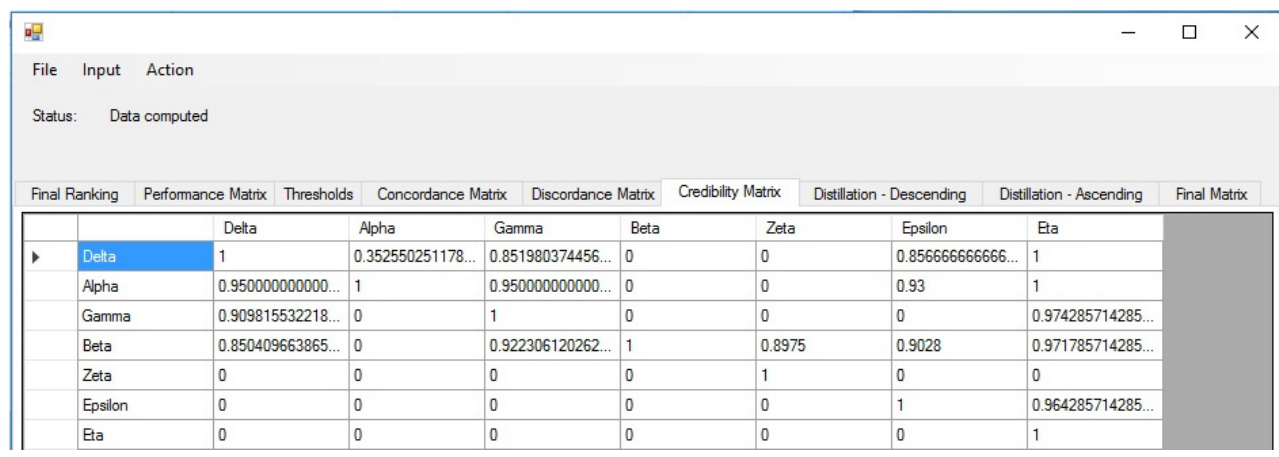

Fig. 1. Credibility matrix.

The credibility index aggregates the total concordance and discordance indices, indicating whether the outranking hypothesis is true or not. It can be noticed that the diagonal of the credibility matrix is the unity because the alternative is compared to itself. Taking, for instance, the example of alternatives Gamma and Alpha, there are no arguments that Gamma outranks Alpha overall $\left(\mathrm{S}_{(\mathrm{Gamma}}\right.$, Alpha) $\left.)=0\right)$, while there are some high chances that supplier Alpha outranks supplier Gamma $\left(\mathrm{S}_{(\mathrm{Alpha}, \mathrm{Gamma})}=0.95\right)$. The next step is to explore this matrix. In order to rank the alternatives, the application is exploiting the outranking degrees by the descending and ascending distillation procedures, which lead to two complete pre-classifications. The descending distillation is shown in fig. 2 (a).

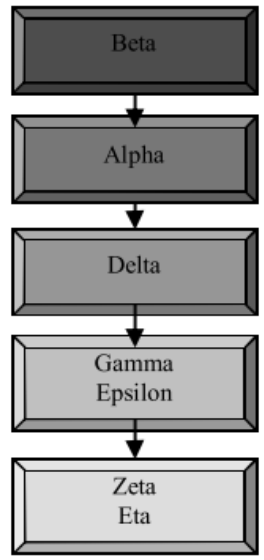

(a)

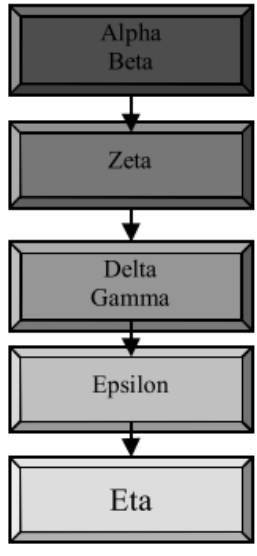

(b)

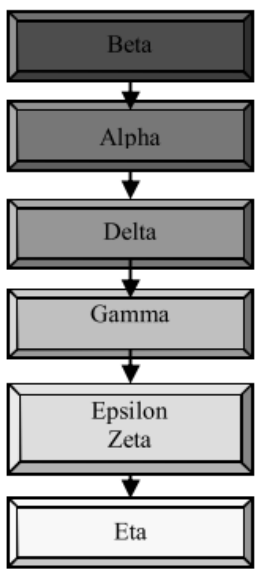

(c)

Fig. 2. Descending distillation (a), ascending distillation (b), final ranking (c).

The descending distillation consists of selecting the best ranked alternatives initially and ending with the worst. The best alternative (Beta) is taken out from the credibility matrix, and then the above step is gradually repeated for the remaining alternatives. The procedure ends when each alternative is assigned a rank. The result of descending distillation showed preference for Beta, followed by Alpha, Delta, Gamma, Epsilon, Zeta and Eta. Regarding the supplier Gamma and Epsilon, as well as Zeta and Eta, there was no preference between them. The ascending distillation, illustrated in fig. 2 (b), uses the same procedure as the descending one, but with successive removal of the worst alternative. The ascending distillation showed that Beta and Alpha were ranked as the best options, followed by Zeta, Gamma, Delta, Epsilon and Eta. Regarding the supplier Delta and Gamma, there was no preference between them. The final ranking is obtained by calculating the intersection of the two pre-classifications, as depicted in fig. 2 (c). It is noticed that Beta was preferred 
over the other suppliers, being the most adequate solution. Regarding variants Epsilon and Zeta, there was no preference between them. At the other extreme, Eta is positioned at the bottom of the ranking, which denotes that it represents the least preferred supplier.

\section{Conclusions}

The supplier selection process is one of the most important decision making problems in the supply chain management. The selecting process is critical for enhancing the company's competitiveness, and requires the assessment of different alternative suppliers based on different criteria.

In this paper, a practical application of a multiple criteria decision making methods, namely the ELECTRE III method, is proposed to deal both with the quantitative and qualitative criteria and to select the suitable supplier effectively. The proposed decision making model has been applied to a supplier selection process of a company working in the field of flexible packaging production. Seven suppliers have been identified and assessed according to twenty three criteria that meet stakeholders' expectations. By running the developed application, the final ranking of suppliers was obtained. The results reveal that ELECTRE III method may be a very useful tool to support managers in solving supplier selection problems.

\section{References}

1. A. Sanayei, S.F. Mousavi, A. Yazdankhah, Expert Syst. Appl., 37, 7, (2010)

2. S.I. Omurca, Appl. Soft Comput., 13, 8, (2013)

3. C.-T. Chena, C.-T. Lin, S.-F. Huangb, Int. J. Prod. Econ., 102, 13, (2006)

4. G. Bruno, E. Esposito, A. Genovese, M. Simpson, Expert Syst. Appl., 43, 15, (2016)

5. Z.H. Che, H.S. Wang, Comput. Ind. Eng., 55, 24, (2008)

6. D.M. Lee, P.R. Drake, Int. J. Prod. Res., 48, 32, (2010)

7. W. Ho, X. Xiaowei, K.D. Prasanta, Eur. J. Oper. Res., 202, 9, (2010)

8. T. Peri'c, Z. Babi'c, I. Ve`za, Int. J. Comput. Integr. Manuf., 26, 14, (2013)

9. R.H. Lin, Appl. Math. Model., 33, 7, (2009)

10. A. Hadi-Vencheh, M. Niazi-Motlagh, Int. J. Comput. Integr. Manuf., 24, 9, (2011)

11. M. Sevkli, Int. J. Prod. Res., 48, 13, (2010)

12. Y.-H. Chen, T.-C. Wang, C.-Y. Wu, Expert Syst. Appl., 38, 7, (2011)

13. M.N. Mokhtarian, A. Hadi-Vencheh, Appl. Soft Comput., 12, 10, (2012)

14. M. Agha Mohammad Ali Kermani et al., Int. J. Comput. Integr. Manuf., 25, 9, (2012)

15. C.-T. Lin, C.-B. Chen, Y.-C. Ting, Expert Syst. Appl., 38, 6, (2011)

16. B.-M. Hsu, C.-Y. Chiang, M.-H. Shu, Expert Syst. Appl., 37, 9, (2010)

17. M. Yu, M. Goh, H. Lin, Eur. J. Oper. Res., 219, 7, (2012)

18. T.J. Kull, S. Talluri, IEEE Trans. Eng. Manag., 55, 11, (2008)

19. L. Li, Z.B. Zabinsky, Int. J. Prod. Econ., 134, 13 (2011)

20. C. Basnet, J.M.Y. Leung, Comput. Oper. Res., 32, 14, (2005)

21. S.H. Ghodsypour, C. O’Brien, Int. J. Prod. Econ., 73, 13, (2001)

22. A.F. Guneri, T. Ertay, A. Yücel, Expert Syst. Appl., 38, 11, (2011)

23. M. Tseng, Appl. Soft Comput. J., 11, 10, (2011)

24. C.C. Lee, C. Ouyang, Expert Syst. Appl., 36, 10, (2009)

25. L. Ferreira, D. Borenstein, Expert Syst. Appl., 39, 11, (2012)

26. X. Guo, Z. Yuan, B. Tian, Expert Syst. Appl., 36, 8, (2009)

27. F. Faez, S.H. Ghodsypour, C. O’Brien, Int. J. Prod. Econ., 121, 14, (2009)

28. Y.L. Tsai, Y.J. Yang, C.-H. Lin, Expert Syst. Appl., 37, 9, (2010) 
29. X. Wang, E. Triantaphyllou, Omega, 36, 19, (2008)

30. G.A. Montazer, H.Q. Saremi, M. Ramezani, Expert Syst. Appl., 36, 11, (2009)

31. C.E.D. Infante et al., J. Clean. Prod., 52, 12, (2013)

32. M.K. Janiaka, J. Żakb, Transport. Res. Proc., 3, 10, (2014)

33. T.M. Mro'z, Appl. Therm. Eng., 28, 9, (2008)

34. M. Cristea, C. Cristea, Proceedings of the Annual Sessions of Scientific Papers "IMT Oradea", 6, (2016) 